\title{
Changes in complex spike activity during classical conditioning
}

\author{
Anders Rasmussen ${ }^{1,2}$ *, Dan-Anders Jirenhed ${ }^{1,2}$, Daniel Z. Wetmore ${ }^{3}$ and Germund Hesslow ${ }^{1,2}$ \\ 1 Department of Experimental Medical Science, Associative Learning Group, Lund University, Lund, Sweden \\ ${ }^{2}$ Linneaus Center CCL, Lund University, Lund, Sweden \\ ${ }^{3}$ Department of Physics, James H. Clark Center for Biomedical Engineering and Sciences, Stanford University, Stanford, CA, USA
}

Edited by:

Takao K. Hensch, Harvard

University, USA

\section{Reviewed by:}

Chris I. De Zeeuw, Erasmus MC, Netherlands

Clement Lena, Ecole Nationale

Supérieure, France

Paul Dean, University of

Sheffield, UK

Tom J. H. Ruigrok, Erasmus MC

Rotterdam, Netherlands

*Correspondence:

Anders Rasmussen, Department of Experimental Medical Science,

Associative learning group, Lund University, Sölvegatan 19, BMC

F10, 22184 Lund, Sweden

e-mail:Anders.Rasmussen@

med.lu.se
The cerebellar cortex is necessary for adaptively timed conditioned responses (CRs) in eyeblink conditioning. During conditioning, Purkinje cells acquire pause responses or "Purkinje cell CRs" to the conditioned stimuli (CS), resulting in disinhibition of the cerebellar nuclei $(\mathrm{CN})$, allowing them to activate motor nuclei that control eyeblinks. This disinhibition also causes inhibition of the inferior olive (IO), via the nucleo-olivary pathway $(\mathrm{N}-\mathrm{O})$. Activation of the $\mathrm{IO}$, which relays the unconditional stimulus (US) to the cortex, elicits characteristic complex spikes in Purkinje cells. Although Purkinje cell activity, as well as stimulation of the $\mathrm{CN}$, is known to influence $\mathrm{IO}$ activity, much remains to be learned about the way that learned changes in simple spike firing affects the IO. In the present study, we analyzed changes in simple and complex spike firing, in extracellular Purkinje cell records, from the $\mathrm{C} 3$ zone, in decerebrate ferrets undergoing training in a conditioning paradigm. In agreement with the N-O feedback hypothesis, acquisition resulted in a gradual decrease in complex spike activity during the conditioned stimulus, with a delay that is consistent with the long $\mathrm{N}-\mathrm{O}$ latency. Also supporting the feedback hypothesis, training with a short interstimulus interval (ISI), which does not lead to acquisition of a Purkinje cell $\mathrm{CR}$, did not cause a suppression of complex spike activity. In contrast, observations that extinction did not lead to a recovery in complex spike activity and the irregular patterns of simple and complex spike activity after the conditioned stimulus are less conclusive.

Keywords: inferior olive, nucleo-olivary pathway, complex spikes, purkinje cells, in vivo electrophysiology, eyeblink conditioning, oscillations, interstimulus interval

\section{INTRODUCTION}

In eyeblink conditioning, repeated pairings of an originally neutral conditional stimulus (CS) and an unconditional, reflexeliciting stimulus (US), results in acquisition of a conditioned response (CR), occurring just before the expected US onset. This CR can be extinguished by repeatedly presenting the CS alone (Kehoe and Macrae, 2002). It is well established that eyeblink conditioning is critically dependent on the cerebellum (McCormick and Thompson, 1984; Bracha et al., 2009), and that the cerebellar cortex is necessary for generating adaptively timed CRs (Yeo et al., 1984; Hesslow and Yeo, 2002; Kellett et al., 2010). During conditioning, Purkinje cells, which provide the sole output from the cerebellar cortex, acquire a pause response, a "Purkinje cell CR" (Figures 1C, 2A,E), that shares many features with learned eyeblinks (Jirenhed et al., 2007; Jirenhed and Hesslow, 2011a,b). Purkinje cells receive information about the CS via mossy fibers, synapsing on granule cells that send parallel fibers to Purkinje cell dendrites (Steinmetz et al., 1986; Hesslow et al., 1999). Information about the US arrives via the climbing fibers originating in the inferior olive (IO; Mauk et al., 1986). Since Purkinje cells are inhibitory, a pause response will cause disinhibition of their target neurons in the cerebellar nuclei (CN; De Zeeuw and Berrebi, 1995), allowing them to initiate a motor response (Hesslow, 1994a; Heiney et al., 2014).

In addition, disinhibition of the $\mathrm{CN}$ causes activation of the nucleo-olivary pathway (N-O; Graybiel et al., 1973). There is compelling evidence that this pathway is GABAergic (de Zeeuw et al., 1988; Nelson and Mugnaini, 1989; Barmack, 1996) and that it exerts a strong inhibitory effect on the IO (Hesslow, 1986; Andersson et al., 1988; Svensson et al., 2006; Bazzigaluppi et al., 2012; Bengtsson and Hesslow, 2013). The evidence also suggests that the $\mathrm{N}-\mathrm{O}$ fibers form a closed loop, that is, they target those olivary cells that are part of the same microcomplex (Apps and Garwicz, 2005). It was proposed by Andersson et al. (1988) that the $\mathrm{N}-\mathrm{O}$ fibers allow the cerebellum to give negative feedback to the IO, either for stabilizing the background firing of Purkinje cells or for stabilizing learning (Andersson and Hesslow, 1987; Andersson et al., 1988). In accordance with the view that the climbing fibers from the IO transmit teaching signals to the cerebellum, such as the US in classical conditioning, an output signal from the $\mathrm{CN}$ to the motor system would be accompanied by an inhibitory signal to the IO to suppress the teaching command and further learning. 
A large number of studies have pursued this idea and provided evidence for the feedback hypothesis. Thus, it has been shown that the IO is indeed suppressed when conditioned responses (CRs) are being emitted and that activation of the N-O pathway can cause extinction of a learned response (Sears and Steinmetz, 1991; Hesslow and Ivarsson, 1996; Apps and Lee, 2002; Bengtsson et al., 2007; Chaumont et al., 2013). Other behavioral phenomena, related to learning, such as extinction (Medina et al., 2002) and blocking (Kim et al., 1998), have also been ascribed to N-O inhibition.

Although a lot has been learned about the $\mathrm{N}-\mathrm{O}$ projection (Bengtsson and Hesslow, 2013), many important questions have remained unanswered: How does the learned Purkinje cell CR compare to N-O stimulation in its ability to influence IO activity? Is the delay between the Purkinje cell CR and the IO inhibition consistent with the long delay in the N-O pathway (Hesslow, 1986; Svensson et al., 2006)? Does IO activity increase during extinction, when the Purkinje cell CR disappears? Does reduced simple spike firing in a Purkinje cell cause inhibition of IO neurons projecting to that same Purkinje cell? Studying changes in complex spike frequency during acquisition and extinction of a Purkinje cell $\mathrm{CR}$ can address these questions because complex spikes reflect IO activity. Further clarification of the relationship between learned changes in Purkinje cell activity and complex spike frequency can be obtained by analyzing changes after training with short interstimulus intervals (ISIs), which on a behavioral level does not result in learning (Salafia et al., 1980). Mirroring the behavior, Purkinje cell CRs are not acquired for ISIs below $\sim 100 \mathrm{~ms}$, and using a $50 \mathrm{~ms}$ ISI even causes increased Purkinje cell activity (Wetmore et al., 2014). Is this increase in simple spike frequency associated with a similar increase in complex spike frequency? This study aims to answer these questions by examining the effect of learned changes in Purkinje cell simple spikes on complex spike activity.

Information about olivary activity during conditioning is also important for evaluating the main alternatives to the feedback hypothesis. It has been suggested that the N-O pathway controls coupling between olivary cells and that firing in specific ensembles of these cells are the main drivers of well timed movements (Jacobson et al., 2008). The temporal pattern of complex spikes during one of the best-studied examples of an adaptively timed cerebellar response would provide a test of this hypothesis.

\section{MATERIALS AND METHODS}

The experimental setup is illustrated in Figure 1A. Subjects were 28 male ferrets $(0.6-1.5 \mathrm{~kg})$, initially anesthetized in a mixture of $\mathrm{O}_{2}$ and air, with 1.5-2\% isoflurane (Baxter Medical, Kista, Sweden), subsequently replaced by propofol $(10 \mathrm{mg} / \mathrm{ml}$ Diprivan; AstraZeneca, Södertälje, Sweden) intravenously. Blood pressure, $\mathrm{CO}_{2}$, and temperature were kept within physiological limits throughout the experiment. After the head was fixed in a stereotaxic frame and the skull opened on the left side, the caudal two thirds of the cerebral hemisphere was removed by aspiration, exposing the anterior cerebellar cortex and the colliculi. Animals were decerebrated by sectioning the brainstem with a blunt spatula 1-2 mm rostral to the superior colliculus. After decerebration, anesthesia was discontinued. With the cerebellum and colliculi exposed, a pool was constructed of cotton reinforced agar and filled with high-density perfluoro carbon liquid (FC-40 Fluorinert; 3M, Zwijndrecht, Belgium). To achieve high stability, ferrets were curarized, artificially ventilated, and were kept hanging by the spine, with the head fixed in the stereotaxic frame. A bilateral pneumothorax was performed in order to minimize chest movements. After removal of the dura, the cerebellar surface was covered with agarose gel $(20 \mathrm{mg} / \mathrm{ml})$ to provide recording stability and prevent edema near the site of recording. For additional details on surgical procedures see Jirenhed et al. (2007). This study has been reviewed and approved by the local Swedish Ethical Committee.

\section{STIMULATION OF CEREBELLAR AFFERENTS}

While tracking for all types of cerebellar afferents (IO, inferior and middle cerebellar peduncle), single stimulus pulses were applied and field potentials were recorded in a blink controlling area of the C3 zone of hemispheral lobule VI, identified by previously established criteria (Hesslow, 1994a,b). Only when stimulation elicited a field potential with the right latency and shape (Figure 1B), and at a relatively low stimulus intensity did we proceed with Purkinje cell recordings. Direct stimulation of cerebellar afferents was done with tungsten electrodes (diameter, $100 \mu \mathrm{m}$; deinsulated tip, $50 \mu \mathrm{m})$. The effectiveness of all stimulation sites and stimulus intensities were verified again and adjusted if necessary when recording the activity of single Purkinje cells.

The CS consisted of either peripheral forelimb stimulation or direct mossy fiber stimulation. The forelimb CS was a $300 \mathrm{~ms}$, $50 \mathrm{~Hz}$ stimulus train applied to the ipsilateral forelimb skin (1.5-2.0 mA, $0.5 \mathrm{~ms}$ pulse duration). The mossy fiber CS also consisted of a $300 \mathrm{~ms}, 50 \mathrm{~Hz}$ stimulus train (90-200 $\mu \mathrm{A}, 0.1 \mathrm{~ms}$ pulse duration). The US consisted of climbing fiber stimulation (15$90 \mu \mathrm{A}, 0.1 \mathrm{~ms}$ pulse duration), direct IO stimulation $(70-320 \mu \mathrm{A}$, $0.1 \mathrm{~ms}$ pulse duration), or periorbital stimulation ( $3 \mathrm{~mA}, 0.5 \mathrm{~ms}$ pulse duration). Central US stimulation (climbing fibers and IO) consisted of two $10 \mathrm{~ms}$ stimulus trains delivered with a $20 \mathrm{~ms}$ interval, each consisting of five pulses at $500 \mathrm{~Hz}$. This stimulation protocol was used because it mirrors the natural firing pattern of the IO, which consists of high frequency bursts (Armstrong and Rawson, 1979; Maruta et al., 2007; Mathy et al., 2009). Peripheral stimuli can sometimes elicit a couple of consecutive bursts with an interval of about $20 \mathrm{~ms}$ between each burst (Ekerot et al., 1987). Moreover, these US parameters reliably results in the acquisition of Purkinje cell CRs (Jirenhed et al., 2007), which is not the case if the US consists of a single pulse (Rasmussen et al., 2013). In the remainder of this manuscript we will not distinguish between different types of CS and US stimulation because these have all been shown to induce Purkinje cell CRs.

\section{TRAINING PROTOCOLS}

Because this article is based on data from several different projects, the protocols used across experiments differ slightly from one another. The protocol for the 12 ferrets conditioned with a $300 \mathrm{~ms}$ ISI was analogous to the protocols used in previous experiments in our laboratory (Hesslow and Ivarsson, 1994; Hesslow et al., 1999; Jirenhed et al., 2007), where the last pulse in the CS train coincides with the first pulse in the US train. The 


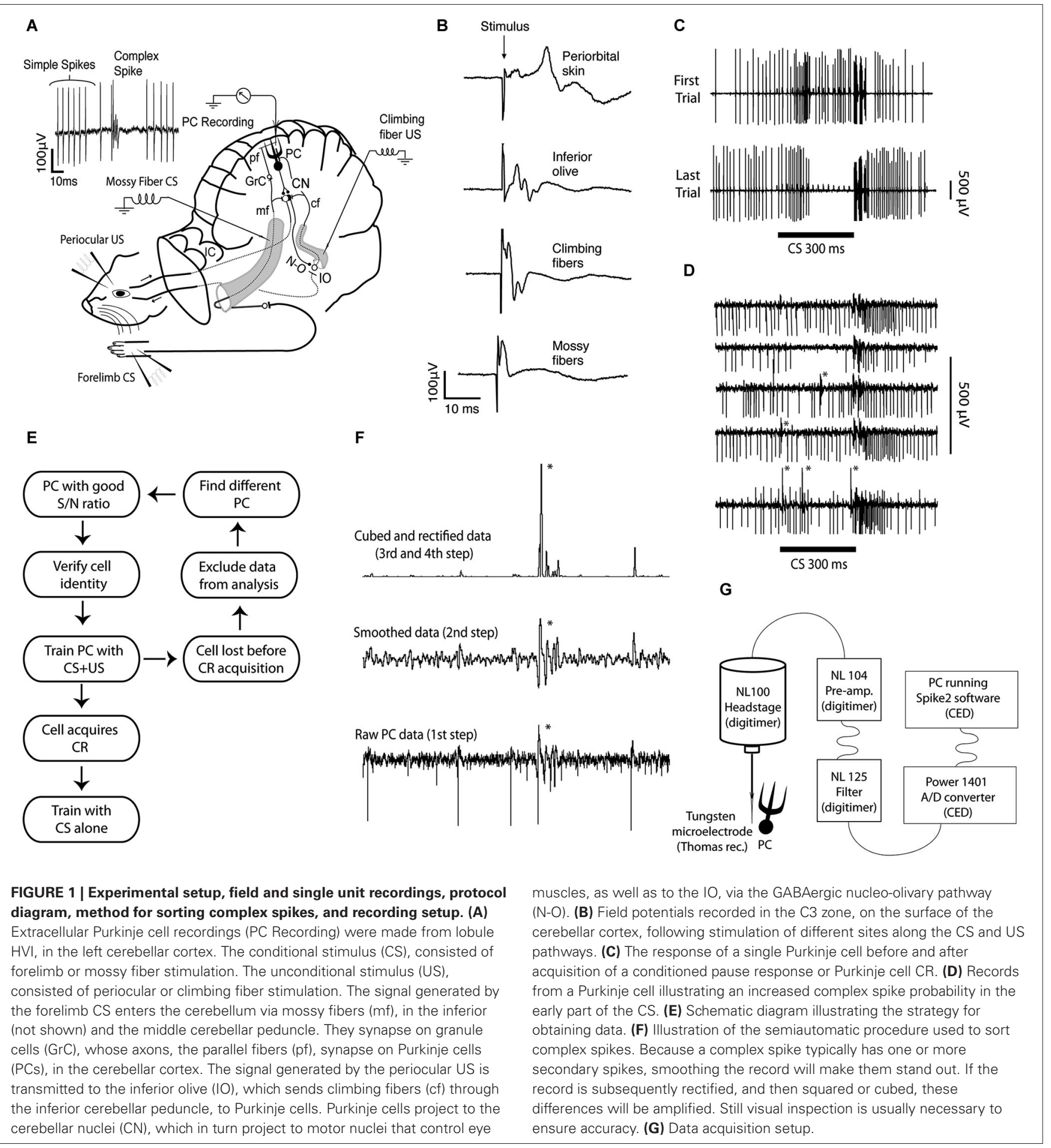

intertrial interval was $15 \mathrm{~s}$. When a cell meeting our pre-defined criteria (see below) had been found, paired CS-US presentations were applied until a Purkinje cell CR developed (Figure 1E). If the cell was lost during training, we discarded data from that cell and tried to find a different cell in which we could study extinction. Following acquisition of a clear Purkinje cell CR we switched to CS alone presentations in order to follow the cell during extinction. The CS and US parameters were kept constant for the 16 ferrets trained with shorter ISIs. Before any paired CSUS presentations were given, 40-60 CS alone trials were recorded. This allowed us to estimate Purkinje cell activity in naïve cells. After the initial CS alone session, paired CS-US presentations, 
with a 50 or $150 \mathrm{~ms}$ ISI, were delivered for approximately $1 \mathrm{~h}$ or 240 trials. After this, another CS alone session followed, and then we proceeded with another paired session. This approach, with interspersed CS alone sessions, allowed us to estimate changes in Purkinje cell activity without influence from the US.

\section{PURKINJE CELL RECORDINGS}

Extracellular single-unit recordings of Purkinje cells, identified by the presence of complex spikes, were performed using quartz glass-coated platinum-tungsten microelectrodes with pulled and ground tips; 30-40 $\mu \mathrm{m}$ metal core diameter (Thomas Recording, Giessen, Germany). All Purkinje cells were located in a blinkcontrolling area of the $\mathrm{C} 3$ zone of the ipsilateral hemispheral lobule VI (Hesslow, 1994a,b). Mossy fiber input from the CS could be verified by increases in simple spike activity on presentation of a $300 \mathrm{~ms}$ stimulus train. The following recording strategy was used to obtain and follow single-cell records: (1) find Purkinje cell (identified by presence of spontaneous complex spikes) in a naive animal; (2) verify identity as eyeblink-controlling cell in C3 by monitoring responses to periorbital stimulation; (3) verify afferent mossy and climbing fiber inputs from the prospective CS and US; (4) establish effective stimulation thresholds for CS and US; (5) start paired CS-US presentations and record during acquisition phase. (a) If recording is sufficiently long and stable to observe a clear learning effect, proceed to step 6. (b) If cell is lost during training, continue with paired CS-US presentations, locate another cell, and go back to step 1; and (6) if an identified Purkinje cell is found that reliably exhibits a clear change in simple spike responses to the CS, proceed with extinction (CS-alone trials), or switch to a different ISI. A record was judged to be from the same Purkinje cell only if (1) the cell was observed continuously throughout the recording; (2) there were no spikes of different but comparable amplitude present at any time; and (3) there were no sudden changes in spike amplitude. The position of the recording electrode occasionally had to be adjusted, but this could usually be done without violating these criteria.

\section{DATA ACOUISITION}

The signal from the microelectrode was fed into a pre-amplifier (NL104) + filter module (NL125), via a NL100 headstage, all from Digitimer Ltd. To eliminate remaining $50 \mathrm{~Hz}$ noise, the signal was passed through a humbug (Digitimer Ltd), before entering a Power 1401 analog/digital converter interface (Cambridge Electronics Design), which sampled the signal at $30 \mathrm{kHz}$ and passed it on, via a USB interface, to a PC running Spike2 v7 software (Figure 1G). Online analysis and offline spike sorting was performed using Spike2, version 7 (Cambridge Electronics Design), and subsequent data analysis was done using custom made Matlab scripts (MathWorks).

\section{COMPLEX SPIKE IDENTIFICATION AND DATA ANALYSIS}

Separating complex spikes from simple spikes and stimulus artifacts in Purkinje cell records involves a number of difficulties: (1) complex spikes and simple spikes may have similar waveforms;

(2) the waveform of complex spikes differs from cell to cell;

(3) complex spike waveforms can change over time within a single record; and (4) the secondary spikes in the complex spikes can vary substantially, especially if the complex spike occurs in proximity to a simple spike or a stimulus artifact. Although sorting complex spikes is difficult, our lab has several decades of experience with studying the IO and examining complex spikes. To minimize the risk of misses and false positives we only used records with a good signal to noise ratio and with distinct complex spikes. The following strategy, illustrated in Figure 1F, was used to make sorting easier: (1) remove DC fluctuations to get a flat baseline; (2) apply a smoothing function that replaces all datapoints with the mean or the median of a specified time window around that data-point (smoothing amplifies complex spikes because, compared to simple spikes, the complex spike waveform deviates from the baseline for a longer period of time); (3) square or cube waveform to further amplify the amplitude difference between complex spikes, simple spikes and stimulus artifacts; and (4) set appropriate thresholds to sort out the complex spikes. It should be stressed that, to ensure accurate complex spike identification, all complex spikes were verified by visual inspection of the recordings. To guard against experimenter bias we sometimes had two individuals sort the same data.

Analyzing changes in complex spike firing rate during conditioning has its own difficulties. Compared to simple spikes, complex spikes occur at a very low frequency, and therefore more data are required to find patterns. Moreover, complex spikes can vary from cell to cell and may also vary over time within a single record (this is true for simple spikes as well). To address these challenges, we split the Purkinje cell record into 50 trial bins. For each bin we normalized the complex spike activity during the CS by dividing it with the background activity, defined as the average activity $600 \mathrm{~ms}$ before the start of the CS. This allowed us to express the complex spike activity within different parts of the CS as a percentage of background activity. When analyzing changes in complex spike activity during acquisition and extinction we were mainly interested in changes during the last $100 \mathrm{~ms}$ of the CS. The reason was that the Purkinje cell CR peaks approximately $180 \mathrm{~ms}$ into the CS (Jirenhed et al., 2007), and any effects on complex spike frequency ought to occur after this. Moreover, we wanted to avoid interference from the CS facilitated complex spikes, which often occur early in the CS. For these two reasons the statistical analysis focused on the last $100 \mathrm{~ms}$ of the CS, although we also report observed changes in other time periods.

\section{RESULTS}

The analysis below is based on a total of 32 cells. Eight Purkinje cells, in eight animals, were recorded from the naïve state until a Purkinje cell CR had been acquired. Five of these eight were also recorded throughout the extinction phase. An additional four cells, which had not been followed during the entire acquisition phase, but which exhibited typical Purkinje cell CRs when found, were also included in the extinction dataset. The analysis of complex spike activity following training with a short ISI, was based on 20 cells trained with a 50, or 150 ms ISI.

\section{COMPLEX SPIKE ACTIVITY DURING ACQUISITION AND EXTINCTION}

The background frequency (mean $\pm \mathrm{sd}$ ) was $1.04 \pm 0.53 \mathrm{~Hz}$, for complex spikes and $69.9 \pm 30.6 \mathrm{~Hz}$ for simple spikes. Repeated 


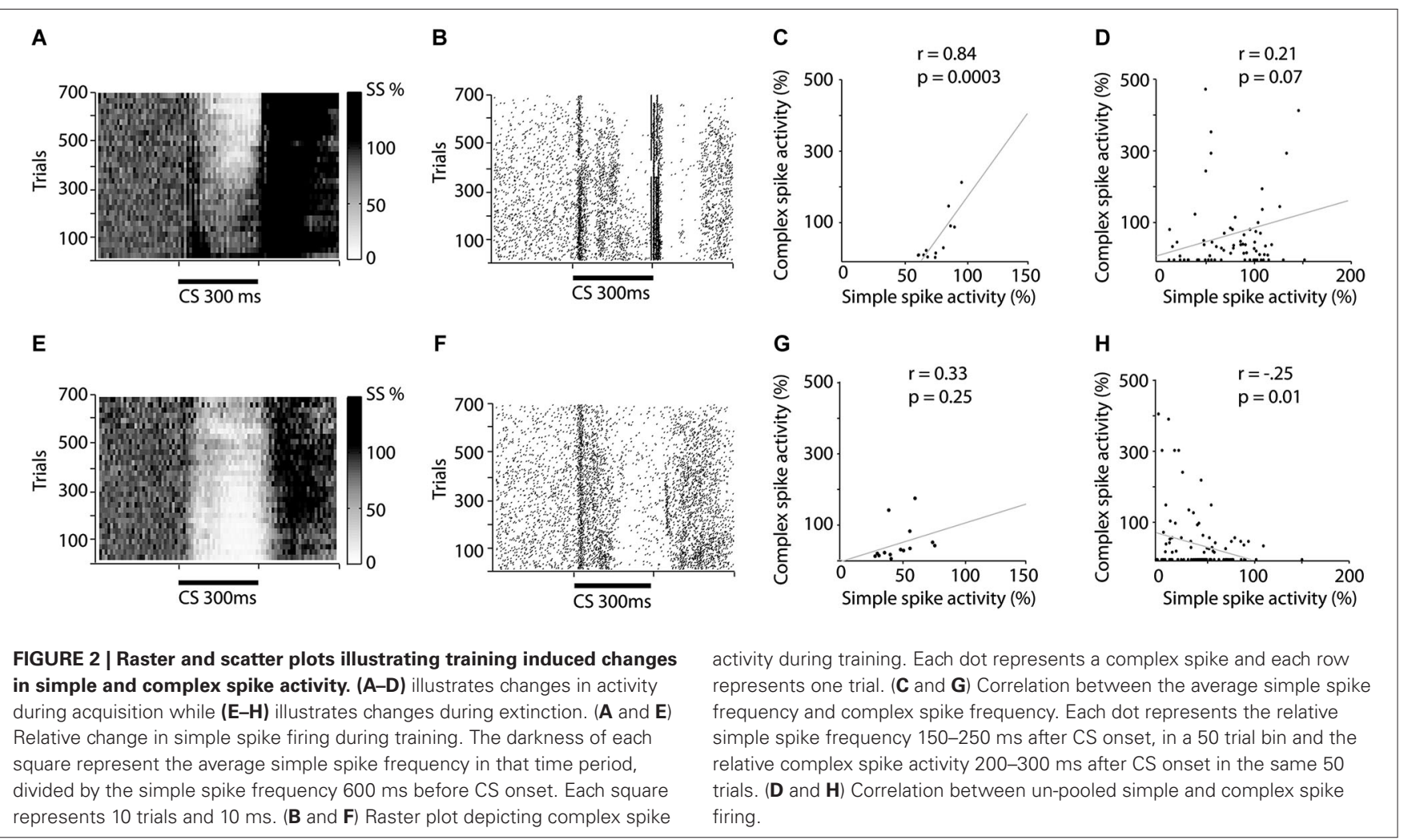

CS-US presentations result in acquisition of a Purkinje cell CR (Figure 2A), with the minimum simple spike activity occurring $180 \mathrm{~ms}$ after CS onset, when using a $300 \mathrm{~ms}$ ISI. If the CS is subsequently presented alone, this simple spike pause response is gradually extinguished (Figure 2E). Based on these results and previous observations suggesting that simple spike activity influences complex spike activity (Miall et al., 1998; Bengtsson and Hesslow, 2006; Rasmussen et al., 2008), we predicted that acquisition and extinction of a Purkinje cell CR would be associated with a corresponding change in complex spike activity. In other words, our prediction was that the acquisition phase would be associated with a gradually decreasing complex spike firing rate, towards the end of the CS-US interval, and that extinction would be associated with a corresponding increase in the complex spike firing rate.

In line with these predictions, seven of the eight cells undergoing acquisition showed decreased complex spike activity in the last $100 \mathrm{~ms}$ of the CS, following training. This decrease developed gradually as training progressed (Figures $2 \mathbf{B}, 3 \mathbf{3}, \mathbf{B}$ ). During the first 50 trials, the average complex spike frequency in the last $100 \mathrm{~ms}$ of the CS was $127 \%$, relative to background frequency. During training, complex spike activity decreased steadily and after 400 trials it was down to $21 \%$, relative to background. After 600 trials the average frequency was $14 \%$ relative to background. A Wilcoxon matched-pairs test confirmed that there was a difference in complex spike activity between the first and last 50 trials of acquisition ( $W=-28, n_{1}=n_{2}=8, p=0.0156$, two-tailed).

Nine Purkinje cells, with distinct complex spikes, were recorded for a sufficient amount of time to observe extinction of the Purkinje cell CR (Figure 2E). Changes in complex spike activity during the extinction phase were characterized by a high degree of variability (Figures 2F, 3A,C). Only four of nine cells showed increased complex spike activity as a result of extinction. Given that these four cells were all among the five cells that we managed to hold for at least 650 trials, it remains a possibility that extinction of the complex spike suppression simply requires more time. Overall, there was no statistically significant change in complex spike activity during extinction $\left(W=17, n_{1}=n_{2}=9\right.$, $p=0.3594$, two-tailed).

If simple spike activity in Purkinje cells influence subsequent complex spike activity, one would expect a positive correlation between the simple and complex spike activity in the latter part of the CS. To test this we calculated the correlation between simple spike activity, 150-250 ms after CS onset, and complex spike activity, 200-300 ms after CS onset, in 50 trial bins throughout acquisition and extinction. The reason for using these time periods for simple and complex spikes was that the complex spike suppression tends to appear later than the simple spike pause. For acquisition there was indeed a positive correlation between the average number of simple spikes and the average number of complex spikes, in a given 50 trial bin (Figure 2C).

However, surprisingly, during the extinction phase there was no statistically significant correlation (Figure 2G). Because averaging over cells can mask effects, which may be present within cells, we also did an analysis on un-pooled data. This analysis revealed a marginally significant correlation during acquisition (Figure 2D), and a surprising negative correlation during the extinction phase (Figure $2 \mathbf{H}$ ). 

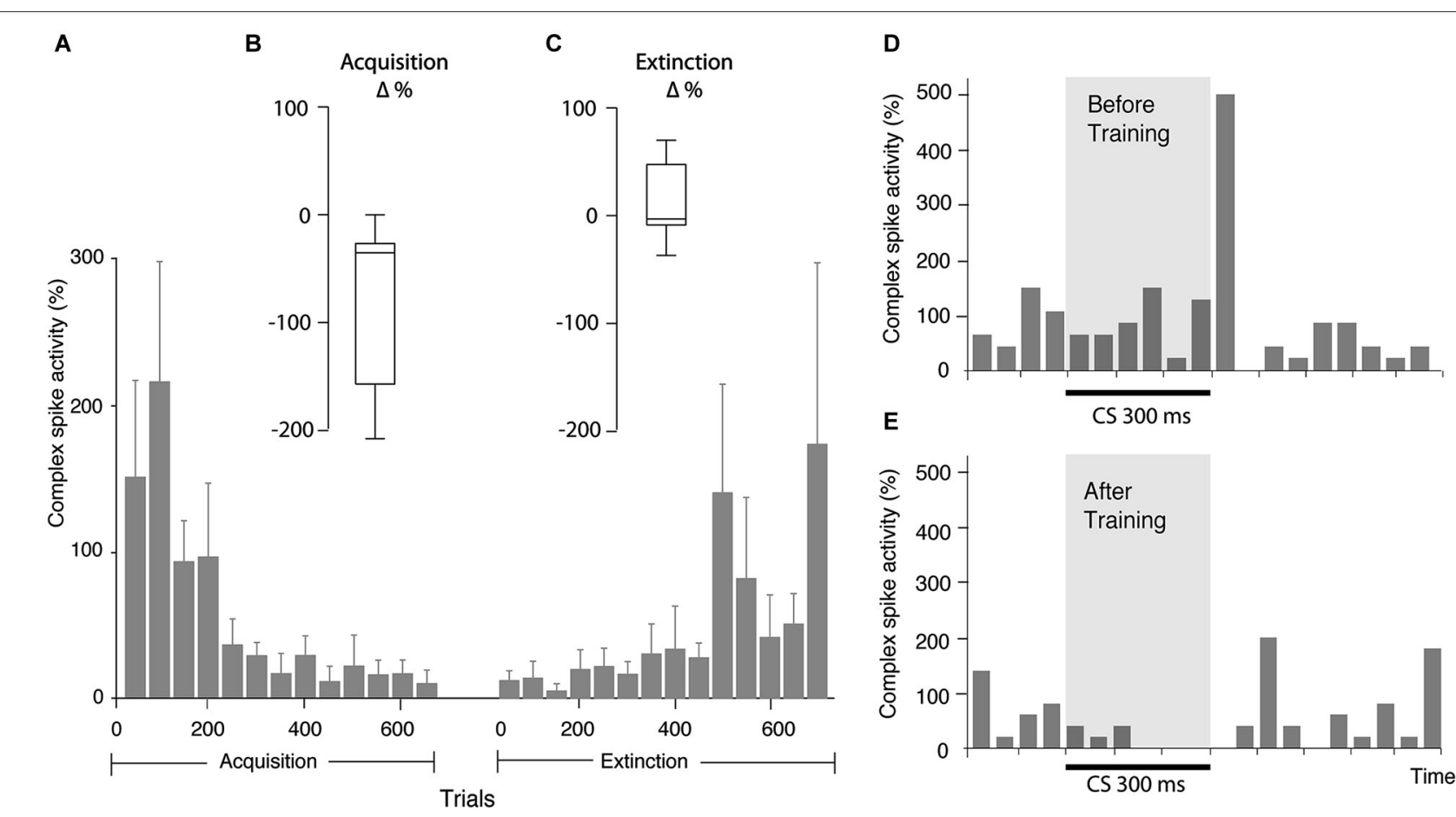

FIGURE 3 | Changes in complex spike activity as a result of training.

(A) Bar chart illustrating complex spike activity (mean \pm SEM), relative to complex spike activity before CS onset, in consecutive bins, each consisting of 50 trials. Since all cells were not followed for the same number of trials, the bars representing the beginning of acquisition and extinction are averages of more cells than the bars representing the latter part of the process. Every bar is based on data from at least three cells.
(B) Distribution of change in complex spike activity between the first 50 and last 50 trials of the acquisition phase $(n=8)$. (C) Distribution of the change in complex spike activity between the first 50 and last 50 trials of the extinction phase $(n=9)$. (D) Bar chart illustrating complex spike frequency in the first 100 trials in the acquisition phase. (E) Complex spike activity in the same cell in the first 100 trials in the extinction phase. Binsize is $50 \mathrm{~ms}$.

\section{CS FACILITATED COMPLEX SPIKES}

In 10 of 12 Purkinje cells trained with $300 \mathrm{~ms}$ ISI, there was a substantial increase in complex spike activity in the first $\sim 100 \mathrm{~ms}$ of the CS, which was particularly pronounced in the first 10$20 \mathrm{~ms}$ (Figures 1D, 2B,F). On average complex spikes appeared in this time window in 4 out of 10 trials, which is four times higher than the natural background firing-rate. The magnitude of this increase varied between cells. In a few cells there were no CS facilitated complex spikes, whereas other cells had CS facilitated complex spikes on almost every trial. This finding raised the question of whether these early CS facilitated complex spikes had any influence on the complex spike frequency in the latter part of the CS? Was the complex spike suppression in the last $100 \mathrm{~ms}$ of the CS simply a rebound inhibition, caused by early CS facilitated complex spikes?

Several observations suggested that this was not the case. The two cells that did not have CS facilitated complex spikes still exhibited a suppression of complex spikes in the last $100 \mathrm{~ms}$ of the CS (Figures 3D,E). Moreover, whereas the complex spike suppression developed gradually, the frequency of complex spikes in the early part of the CS did not change as training progressed. If the complex spike suppression was cause by the early increase in complex spikes, it should have been present when training began.

In addition, we examined whether exclusion of trials with early complex spikes had any effect on the complex spike suppression in the last $100 \mathrm{~ms}$ of the CS. We found that even after excluding all trials with CS facilitated complex spikes, there was still a complex spike suppression in the end of the CS (Figure 4). Indeed, the average complex spike activity, after acquisition, in the last $100 \mathrm{~ms}$ of the CS was $16 \%$ in trials with one or more complex spikes in the early part of the CS and only 7\% in trials without complex spikes in the early part of the CS. These observations show that the CS facilitated complex spikes did not cause the subsequent complex spike suppression.

The fact that the increase in complex spike activity, in the early part of the CS, was equally large throughout training also suggests that this increase cannot be the cause of the timed simple spike pause response that drives the overt CR. This point is further strengthened by the observation that whereas simple spike activity correlates with subsequent complex spike activity, there was no correlation between the complex spike activity and the subsequent simple spike activity (Table $\mathbf{1}$ ).

\section{TIME COURSE OF COMPLEX SPIKE SUPPRESSION}

Direct stimulation of the N-O pathway results in inhibition of the IO, mediated by release of GABA onto IO synapses. Because the release of GABA is mainly asynchronous (Best and Regehr, 2009), there is an unusually long delay between activation of the N-O pathway and the maximum inhibition of the IO (Hesslow, 1986; Svensson et al., 2006). If, as we have argued, Purkinje cell activity 


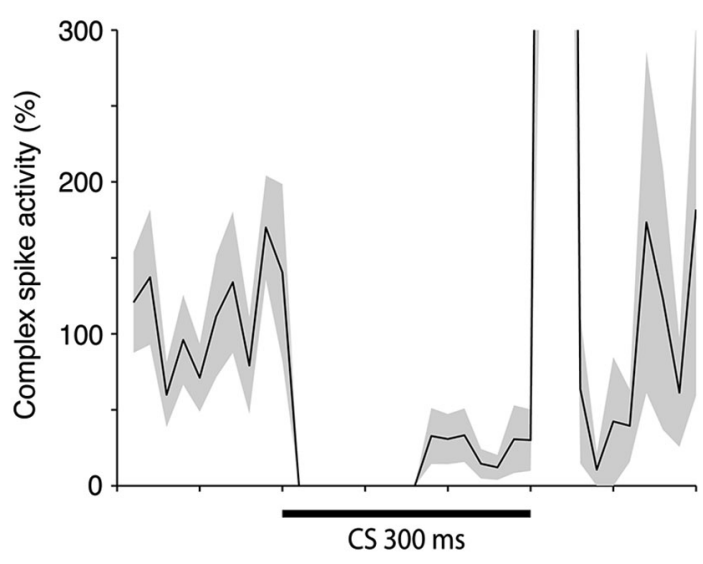

FIGURE 4 | Complex spike activity during the CS when all trials with CS facilitated complex spikes has been excluded. Mean \pm SEM of

relative complex spike activity in 11 cells either at the end of acquisition ( $n=$ $7)$, or in the beginning of extinction $(n=4)$. One cell was excluded from this analysis because it displayed CS facilitated complex spikes on a high proportion of the trials.

influences complex spike activity via the $\mathrm{N}-\mathrm{O}$ pathway, then there ought to be a delay between the Purkinje cell CR and the complex spike suppression.

To estimate the delay between the Purkinje cell CR, and the suppression of the complex spike frequency we averaged complex spike activity in all cells during the last 100 trials of acquisition and the first 100 trials of extinction into $10 \mathrm{~ms}$ bins. In the cells that were recorded during both acquisition and extinction we only looked at acquisition. Following Jirenhed et al. (2007), a suppression was defined as a period in which complex spike activity was below $50 \%$ of the background activity, for at least $50 \mathrm{~ms}$. The maximum suppression was defined as the bin, within a suppression, where complex spike activity was at its minimum. Simple spike activity reached its minimum level $180 \mathrm{~ms}$ after

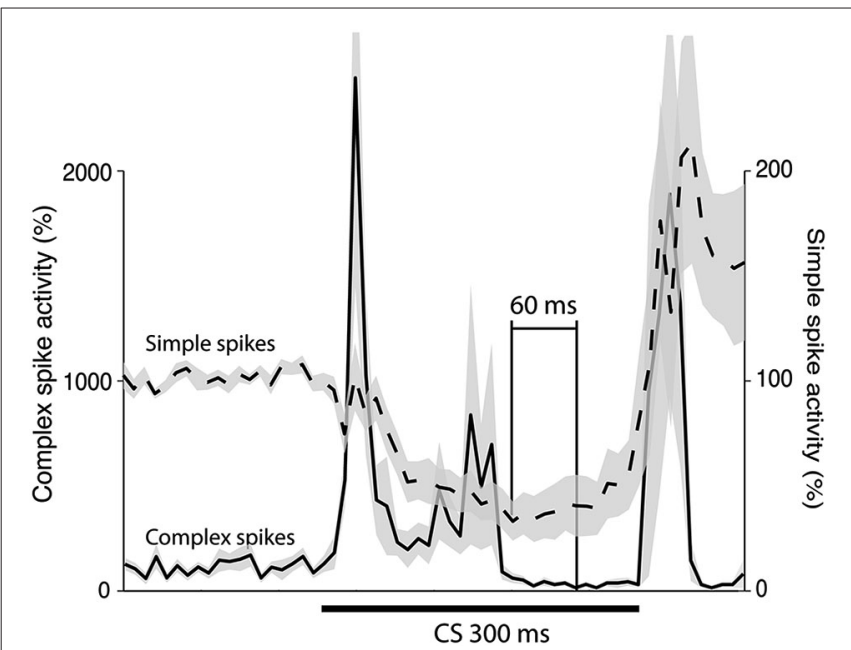

FIGURE 5 | Simple and complex spike activity after training. The plot shows the activity (mean \pm SEM) of 12 Purkinje cells in the last 100 trials of acquisition ( $n=8$ ), or in the first 100 trials of extinction $(n=4)$. For each cell the data was binned in $10 \mathrm{~ms}$ bins and then averaged over all trials. After this had been done for each cell the average profiles illustrated in the figure were constructed. The minimum was defined as the bin with the lowest firing frequency. For the complex spikes there were several bins with zero activity. The minimum in the figure is the earliest of these points.

CS onset. In contrast complex spike activity reached its lowest level $240 \mathrm{~ms}$ after CS onset. Moreover, the activity remained at a low level throughout and sometimes beyond the duration of the CS (Figure 5). This $60 \mathrm{~ms}$ delay is consistent with the long delay of $\mathrm{N}-\mathrm{O}$ inhibition and it corroborates the finding that the correlation between simple and complex spike activity was strongest when the simple spike time window preceded the complex spike time window by at least $50 \mathrm{~ms}$ (Table 1). At the very least, the results suggest that simple spike activity influences subsequent complex spike activity, rather than the other way around.

Table 1 | Correlation between pooled and un-pooled simple and complex spike activity in different $100 \mathrm{~ms}$ time windows during the CS, in the acquisition phase $\left({ }^{*} p<0.05, * * p<0.01, * * * p<0.001\right)$.

\begin{tabular}{|c|c|c|c|c|}
\hline Simple spike time window & Complex spike time window & Delay Complex-Simple & Correlation, population & Correlation, cell-wise \\
\hline 0-100 ms & $200-300 \mathrm{~ms}$ & $200 \mathrm{~ms}$ & $r=0.80, r_{2}=0.63^{* * *}$ & $r=0.25, r_{2}=0.062^{*}$ \\
\hline 50-150 ms & $200-300 \mathrm{~ms}$ & $150 \mathrm{~ms}$ & $r=0.85, r_{2}=0.73 * * *$ & $r=0.25, r_{2}=0.064^{*}$ \\
\hline $100-200 \mathrm{~ms}$ & $200-300 \mathrm{~ms}$ & $100 \mathrm{~ms}$ & $r=0.88, r_{2}=0.78 * * *$ & $r=0.25, r_{2}=0.06^{*}$ \\
\hline $150-250 \mathrm{~ms}$ & $200-300 \mathrm{~ms}$ & $50 \mathrm{~ms}$ & $r=0.84, r_{2}=0.71 * * *$ & $r=0.21, r_{2}=0.045 \mathrm{~ns}$ \\
\hline 200-300 ms & $200-300 \mathrm{~ms}$ & $0 \mathrm{~ms}$ & $r=0.73, r_{2}=0.54^{* * *}$ & $r=0.13, r_{2}=0.017 \mathrm{~ns}$ \\
\hline 0-100 ms & $150-250 \mathrm{~ms}$ & $150 \mathrm{~ms}$ & $r=0.56, r_{2}=0.31^{*}$ & $r=0.19, r_{2}=0.036 \mathrm{~ns}$ \\
\hline $50-150 \mathrm{~ms}$ & $150-250 \mathrm{~ms}$ & $100 \mathrm{~ms}$ & $r=0.64, r_{2}=0.40^{*}$ & $r=0.07, r_{2}=0.005 \mathrm{~ns}$ \\
\hline 100-200 ms & $150-250 \mathrm{~ms}$ & $50 \mathrm{~ms}$ & $r=0.66, r_{2}=0.43^{*}$ & $r=-0.02, r_{2}=0 \mathrm{~ns}$ \\
\hline $150-250 \mathrm{~ms}$ & $150-250 \mathrm{~ms}$ & $0 \mathrm{~ms}$ & $r=0.43, r_{2}=0.19 \mathrm{~ns}$ & $r=-0.05, r_{2}=0 \mathrm{~ns}$ \\
\hline 200-300 ms & $150-250 \mathrm{~ms}$ & $-50 \mathrm{~ms}$ & $r=0.29, r_{2}=0.08 \mathrm{~ns}$ & $r=-0.15, r_{2}=0.02 \mathrm{~ns}$ \\
\hline $0-100 \mathrm{~ms}$ & $100-200 \mathrm{~ms}$ & $100 \mathrm{~ms}$ & $r=0.08, r_{2}=0 \mathrm{~ns}$ & $r=0.047, r_{2}=0 \mathrm{~ns}$ \\
\hline $50-150 \mathrm{~ms}$ & $100-200 \mathrm{~ms}$ & $50 \mathrm{~ms}$ & $r=0.11, r_{2}=0.01 \mathrm{~ns}$ & $r=-0.02, r_{2}=0.0 \mathrm{~ns}$ \\
\hline 100-200 ms & $100-200 \mathrm{~ms}$ & $0 \mathrm{~ms}$ & $r=0.10, r_{2}=0.01 \mathrm{~ns}$ & $r=-0.02, r_{2}=0.04 \mathrm{~ns}$ \\
\hline $150-250 \mathrm{~ms}$ & $100-200 \mathrm{~ms}$ & $-50 \mathrm{~ms}$ & $r=-0.12, r_{2}=0.01 \mathrm{~ns}$ & $r=-0.31, r_{2}=0.10 * *$ \\
\hline 200-300 ms & $100-200 \mathrm{~ms}$ & $-100 \mathrm{~ms}$ & $r=-0.17, r_{2}=0.03 \mathrm{~ns}$ & $r=-0.34, r_{2}=0.11^{* *}$ \\
\hline
\end{tabular}




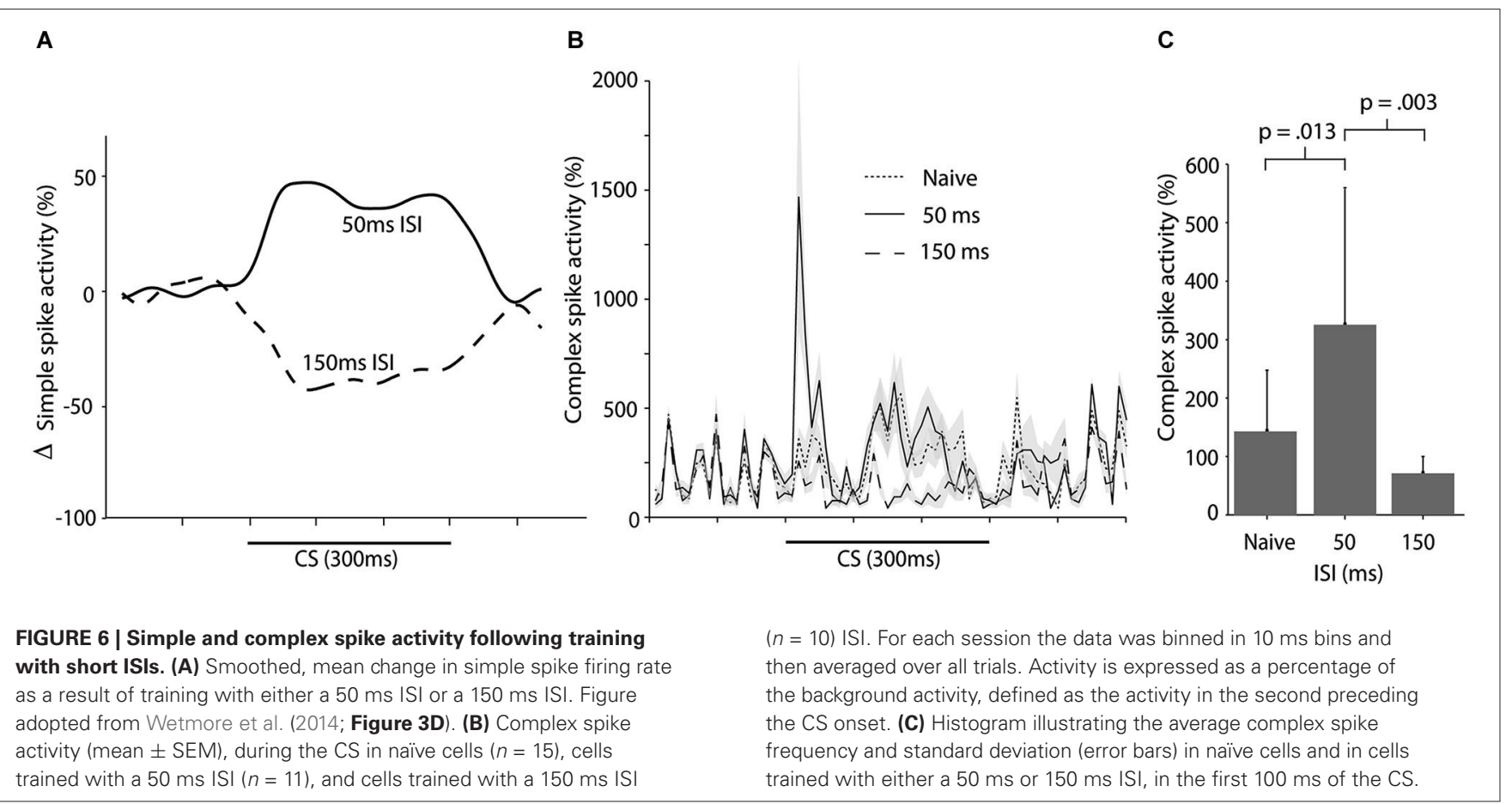

COMPLEX SPIKE ACTIVITY FOLLOWING TRAINING WITH SHORT ISIs

We have recently shown that training with a $50 \mathrm{~ms}$ ISI results in increased simple spike activity during the CS (Wetmore et al., 2014; Figure 6A). Here we wanted to examine whether this increase in simple spike activity resulted in a corresponding increase in complex spike activity. To test this, we analyzed 35 CS alone sessions from 20 cells in 16 animals. These CS alone sessions were recorded at regular intervals, interspersed throughout

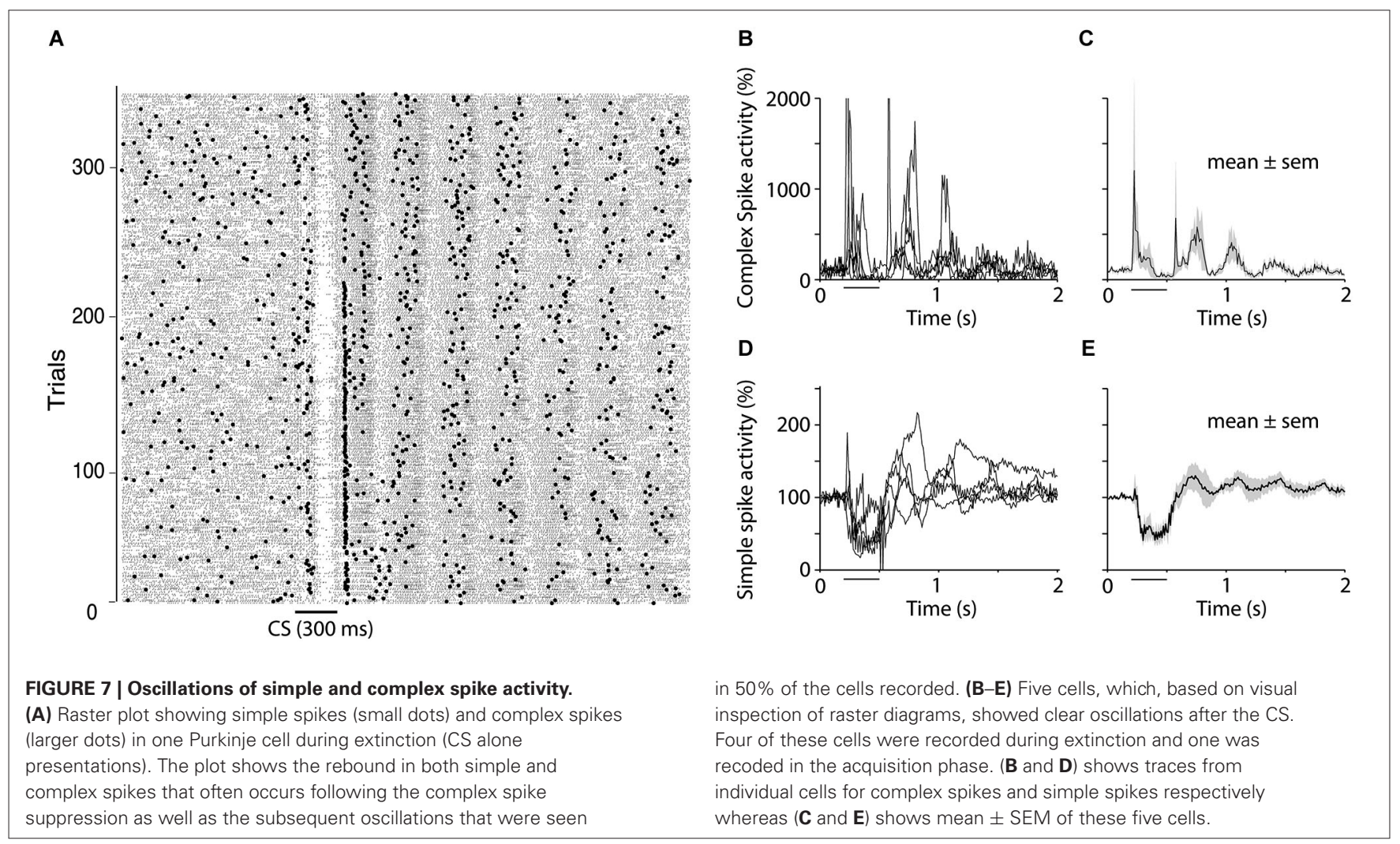


training with different ISIs. There was no statistically significant difference between complex spike activity in naïve cells, and cells trained with a $50 \mathrm{~ms}$ ISI, over the whole CS period, $t_{(24)}=1.577$, $p=0.13$ (Figure 6B). However, an analysis confined to the first $100 \mathrm{~ms}$ of the CS, did reveal a statistically significant increase in complex spikes between naïve cells and cells trained with a $50 \mathrm{~ms}$ ISI, $t_{(24)}=2.68, p=0.013$ (Figure 6C).

In contrast, training with a $150 \mathrm{~ms}$ ISI, which supports acquisition of Purkinje cell CRs, lead to reduced complex spike activity when compared with naïve cells (and cells trained with a $50 \mathrm{~ms}$ ISI). This suppression was apparent in the first $100 \mathrm{~ms}$ of the CS, $t_{(23)}=2.11, p=0.046$, and over the entire CS period, $t_{(23)}=$ $3.57, p=0.002$ (Figures 6B,C). Note that, although training with a $50 \mathrm{~ms}$ ISI resulted in increased complex spike activity in the first $100 \mathrm{~ms}$ of the CS, there was no suppression of complex spikes in the latter part of the CS (Figure 6B). This reaffirms the conclusion that the complex spike suppression seen during training with a $300 \mathrm{~ms}$ ISI, is not a rebound inhibition caused by the CS facilitated complex spikes. If this had been the case, then such a rebound should have been present following training with a $50 \mathrm{~ms}$ ISI as well.

\section{OSCILLATIONS}

In addition to the results presented above, we observed that the suppression of complex spikes at the end of the CS, was often followed by oscillations in both simple and complex spike activity. Complex spikes elicited by the US were not the cause of these because they also occurred on CS alone trials. Figure 7 shows simple and complex spike activity in five cells that exhibited clear oscillations in complex spike activity. The relative timing of the oscillations in simple and complex spikes was inconsistent. The first peak in complex spike activity occurred $60 \mathrm{~ms}$ after the first peak in simple spike activity, which is consistent with the delay between the simple and complex spike suppression during the CS. However, subsequent peaks did not follow this pattern. For example, the second peak in complex spike activity came before the second peak in simple spike activity.

\section{DISCUSSION}

Consistent with earlier reports (Sears and Steinmetz, 1991; Hesslow and Ivarsson, 1994), the evidence presented in this paper shows that the IO is suppressed following the emission of a CR. In addition, the evidence shows that this suppression is a consequence of training. This observation, together with the correspondence between the time course of the Purkinje cell CR and the complex spike suppression, supports the view that the suppression of the IO is caused by Purkinje cell CRs disinhibiting the $\mathrm{CN}$ and activating the $\mathrm{N}-\mathrm{O}$ pathway.

To what extent do the firing patterns observed here agree with observations in different setups? While decerebrated ferrets have an intact cerebellum and are capable of acquiring behavioral CRs, if they are not curarized (Hesslow and Ivarsson, 1994), there is a possibility that decerebration can disrupt other brain areas that can affect cerebellar activity. For example, the CN send an excitatory projection to the Nucleus of Darkschewitsch in the midbrain, which in turn sends an excitatory projection to the IO (De Zeeuw and Ruigrok, 1994). If this pathway was damaged, it could alter IO activity, which would affect the results. We have no histological data from these animals, that allow us to examine this possibility, and thus cannot exclude it with certainty. Yet comparison with cats, which have a brainstem very similar to ferrets, suggests that it is unlikely that such damage has occurred in our experiments.

\section{VARIABILITY OF COMPLEX SPIKE RECOVERY DURING EXTINCTION?}

Although extinction is associated with a recovery of simple spike firing during the CS (Jirenhed et al., 2007), changes in complex spike activity were markedly varied in this phase. Only five of the nine cells recorded during extinction had higher activity in the last bin of 50 trials, when compared to the first bin. In the four remaining cells complex spike activity either did not change or increased during extinction. An even more puzzling observation was the negative correlation between simple and complex spike activity in the un-pooled extinction data. Why did the data gathered during extinction deviate from the rest of the dataset?

One possibility is that there really is no difference and that if we had been able to record the cells for longer time periods, we would have seen increased complex spike activity. In support of this view, four of the five cells we recorded for 650 trials, or more, did exhibit increased complex spike firing. Perhaps the biochemical processes responsible for acquisition of the Purkinje cell CR continue for some time after switching to the extinction protocol. Still, this would not explain the absence of a correlation between simple and complex spike activity, which was present during the acquisition phase.

Another possibility is that the variable complex spike recovery during extinction reflects a difference in simple spike activity in other microzones. We know that a cell group in the anterior interpositus nucleus that controls a specific muscle, receives convergent Purkinje cell input from several microzones in the C1, C3 and Y zones (Apps and Garwicz, 2005). This was confirmed in a mapping study of cerebellar cortex of cats, where four microzones controlling blink were found (Hesslow, 1994a), and probably also holds for ferrets (Garwicz, 1997). Our Purkinje cell recordings are all from the same $\mathrm{C} 3$ area, but if the extinction process were slower in other microzones, the disinhibition of the nuclear cells and the consequent suppression of the IO would last longer.

Yet another possibility is that acquisition induces plasticity in the $\mathrm{CN}$ or the IO, which is not as easily reversed, as the plasticity in the Purkinje cells. The fact that re-acquisition is faster than acquisition, on a behavioral level (Napier et al., 1992), as well as in the Purkinje cells (Jirenhed et al., 2007), shows that extinction is not a mirror image of acquisition (Mauk and Ohyama, 2004). It has been suggested that residual plasticity in the $\mathrm{CN}$ is responsible for this rapid re-acquisition or savings (Medina et al., 2001). Could it be that the relative inflexibility of complex spike activity during extinction is a reflection of this residual plasticity?

\section{LATENCY BETWEEN SIMPLE SPIKE AND COMPLEX SPIKE SUPPRESSION}

Direct stimulation of the $\mathrm{N}-\mathrm{O}$ pathway results in inhibition of the IO. According to previous estimates, this inhibition peaks $30 \mathrm{~ms}$ after stimulus onset in ferrets and after $\sim 50 \mathrm{~ms}$ in cats, though the effect persists for several $100 \mathrm{~ms}$ (Hesslow, 
1986; Svensson et al., 2006; Bazzigaluppi et al., 2012; Bengtsson and Hesslow, 2013). We estimated the delay using two different methods. First we plotted the Purkinje cell CR and the complex spike suppression on top of each other (Figure 5). Consistent with the long $\mathrm{N}-\mathrm{O}$ delay, the minimum complex spike activity occurred $60 \mathrm{~ms}$ after the minimum simple spike activity. Furthermore, the complex spike suppression remained strong throughout the CS. Further corroborating evidence was found when we analyzed the correlation between simple and complex spike activity, in different parts of the CS. As shown in Table 1, the correlation was highest when the simple spike window preceded the complex spike window by $50-150 \mathrm{~ms}$. In contrast, complex spike activity did not correlate with subsequent simple spike activity. Our estimate of the $\mathrm{N}-\mathrm{O}$ delay is longer than the $30 \mathrm{~ms}$ suggested by previous results (Svensson et al., 2006), but shorter than the very long delays proposed by Bazzigaluppi et al. (2012). However the 25-40 ms figure is based on direct electrical stimulation of the $\mathrm{N}-\mathrm{O}$ pathway and it is possible that in the absence of direct $\mathrm{N}-\mathrm{O}$ stimulation temporal summation at the $\mathrm{CN}$ or IO level is required to achieve the same IO suppression, and if so, this could explain the extra delay.

What is the functional significance of this unusually long delay? One plausible suggestion is that it maximizes the inhibitory effect of the CR on the US (Lepora et al., 2010). The Purkinje cell CR following training with a $300 \mathrm{~ms}$ ISI, peaks approximately $180 \mathrm{~ms}$ into the CS (Jirenhed et al., 2007). The fact that the Purkinje cell CRs peak before the behavioral CRs is consistent with the suggestion that the Purkinje cell CR generates the behavioral CR. Moreover, the long delay in the $\mathrm{N}-\mathrm{O}$ pathway is consistent with the idea that Purkinje cell CRs inhibit the US. If there had been no delay in the N-O pathway, the inhibition would have occurred too early. In essence, the N-O delay allows for inhibition of the US signal once learning has been achieved (Bengtsson and Hesslow, 2006; Lepora et al., 2010). This hypothesis assumes that, even though the minimum level of complex spike activity occurred $240 \mathrm{~ms}$ after the CS onset, there is still a substantial IO suppression after 300 ms. Based on Figure 2F, from which it is clear that the complex spike suppression persists throughout and even beyond the CS, this assumption appears to be justified.

\section{CS FACILITATED COMPLEX SPIKES}

In the majority of the cells recorded, we observed an increase in complex spike activity during the first 100-150 ms of the CS. Some cells had 10 times higher complex spike activity in the beginning of the CS compared to background, whereas other cells exhibited no change. Why did the CS lead to an increase in complex spikes? One possibility is that the CS directly or indirectly excited the IO. The observation that the CS sometimes induces a $20 \%$ increase in simple spike activity (Jirenhed et al., 2007), together with the fact that the cerebellum has a modular organization, suggests another possible explanation for the CS facilitated complex spikes. Increased firing in a large number of Purkinje cells could lead to disinhibition of the IO, via the N-O pathway, which in turn could increase complex activity. However, the fact that some CS facilitated complex spikes appeared after only $10 \mathrm{~ms}$ suggests that this cannot be the whole explanation.
Whatever the cause, several observations show that the CS facilitated complex spikes did not influence the development of the complex spike suppression. First, in the two cells where CS facilitated complex spikes were absent, complex spike activity was still suppressed (Figures 3D,E). Second, although CS facilitated complex spikes were present throughout the acquisition and extinction phases, the complex spike suppression developed gradually. Third, the complex spike suppression was present even after we excluded all trials with complex spikes in the early part of the CS (Figure 4).

\section{SHORT ISIs}

Purkinje cells trained with a $50 \mathrm{~ms}$ ISI, instead of a Purkinje cell CR, develop an increase in simple spike activity (Wetmore et al., 2014). Consistent with the hypothesis that simple spike activity influences complex spike activity via the $\mathrm{N}-\mathrm{O}$ pathway, there was no decrease in complex spike activity following training with a $50 \mathrm{~ms}$ ISI. In contrast, a $150 \mathrm{~ms}$ ISI, which does support CR acquisition, did lead to a suppression of complex spikes. It thus appears that the complex spike suppression only occurs after training with an ISI that produces a Purkinje cell CR. Because we did not have as much data for the short ISI conditions, we could not estimate the relative timing of the simple and complex spike activity as precisely. Nevertheless, compared to untrained cells and cells trained with a $150 \mathrm{~ms}$ ISI, the cells trained with a $50 \mathrm{~ms}$ ISI did exhibit increased complex spike firing in the first $100 \mathrm{~ms}$ of the CS, suggesting that simple spike activity can modulate complex spike activity in a bidirectional manner.

\section{OSCILLATIONS IN SIMPLE AND COMPLEX SPIKE ACTIVITY}

Oscillatory patterns of neuronal activity, have been observed in many different parts of the brain, including the IO (Llinás and Yarom, 1986; Llinás, 1988). In the IO, these membrane potential oscillations are thought to rely on interactions between neurons connected by gap junctions. The properties of these gap junctions, and hence the interactions between neurons in the IO, in turn depend on activation of glutamatergic NMDA receptors (Mathy et al., 2014), as well as GABAergic input from the CN (Lefler et al., 2014). We observed oscillations in simple and complex spike activity in 5 of 12 cells after the CS (Figure 7). The first peak in complex spike activity occurred $60 \mathrm{~ms}$ after the first peak in simple spike activity, which is consistent with a $\mathrm{N}-\mathrm{O}$ mediated disinhibition of the IO. However, the fact that subsequent peaks did not conform to this pattern suggests that other mechanisms are involved. The frequency of the oscillations resembled the 1-10 Hz sub-threshold oscillations previously described in the IO (Lampl and Yarom, 1993; De Zeeuw et al., 2011), yet, the fact that we did not see any oscillations prior to CS onset, in accordance with previous reports (Keating and Thach, 1995, 1997), suggests that sub-threshold oscillations cannot be the sole cause of the observed complex spike oscillations. Another, not necessarily opposing, possibility is that the oscillations are related to behavioral oscillations, which have been observed in finger movements (Vallbo and Wessberg, 1993), as well as eyelid movements (Gruart et al., 2000). Since our animals were paralyzed while recording Purkinje cell activity, we could not determine 
whether the oscillations in simple and complex spike activity were associated with similar oscillations in the activity of the muscles controlling the eyelid.

\section{THE OLIVE AS A MOVEMENT TIMER}

It has been proposed by some authors that the climbing fiber system functions as a generator of temporal patterns and that these patterns can be used for movement timing (Llinás et al., 2002; Jacobson et al., 2008). Conditioned eyeblinks are prime examples of adaptively timed movements generated by the cerebellum. If the olivary timer hypothesis were true, one would therefore expect the olive to fire in advance of the CR in order to assist in its timing. The fact that the occurrence of an adaptively timed Purkinje cell CR does not seem to depend on the presence of a previous complex spike is a strong argument against the suggestion that the climbing fibers are involved in generating timed movements.

\section{IMPLICATIONS AND LIMITATIONS}

There is an apparent contradiction between the positive correlation between simple spike activity and subsequent complex spike activity that we have shown in this paper and the well-established fact that IO activity, outside the normal range, correlates negatively with simple spike activity. Apart from passing on the US signal, the IO also controls the Purkinje cell's intrinsic spike generator. As a result, high frequency stimulation of the IO or climbing fibers will silence the Purkinje cells, whereas lesioning or blocking the IO results in abnormally high levels of Purkinje cell activity (Colin et al., 1980; Cerminara and Rawson, 2004). We do not know what caused the substantial increase in simple spike activity and the absence of complex spikes, after the US stimulation in the acquisition phase (Figures 2A,B). One possibility however is that the US interferes with the intrinsic spike generator, resulting in an abnormal firing pattern. This would explain why the same pattern is not seen during extinction.

Most work on the role of N-O inhibition in feedback regulation of the IO has dealt with the probability of IO firing, but it now seems clear that the number of impulses (Rasmussen et al., 2013), and in consequence the duration (Yang and Lisberger, 2014) of the climbing fiber signal determines the rate and direction of cerebellar learning (see also Kimpo et al., 2014). This raises the question of whether the $\mathrm{N}$-O feedback signal might modulate the olivary response in a graded manner (Najafi and Medina, 2013; Rasmussen and Hesslow, 2014). While this paper provides strong evidence that learned changes in Purkinje cell activity can affect subsequent IO activity, our recordings did not permit us to assess any effect on the shape of the US elicited complex spikes. The reason is that, in most cells, we used climbing fiber stimulation as a US, thus bypassing the IO and N-O modulation. When we did use a peripheral US, the stimulus artifacts usually masked the complex spikes, which made complex spike identification unreliable. Nevertheless, the IO signal appears to be a crucial variable. For similar reasons, we could not compare our results with the recent report that the N-O pathway synchronizes the IO response and makes it more phasic (Hogri et al., 2014). In the light of this, future research ought to test if Purkinje cell CRs can affect, in a graded manner, the intensity or temporal dynamics of the US induced IO response.

\section{ACKNOWLEDGMENTS}

This work was supported by grants from the Swedish Research Council to The Linneaus Centre for Cognition, Communication and Learning at Lund University (349-2007-8695) and to G. Hesslow (09899) and from the Söderberg, Krapperup and Åhlen foundations.

\section{REFERENCES}

Andersson, G., Garwicz, M., and Hesslow, G. (1988). Evidence for a GABAmediated cerebellar inhibition of the inferior olive in the cat. Exp. Brain Res. 72, 450-456. doi: 10.1007/bf00250590

Andersson, G., and Hesslow, G. (1987). Activity of Purkinje cells and interpositus neurones during and after periods of high frequency climbing fibre activation in the cat. Exp. Brain Res. 67, 533-542. doi: 10.1007/bf00247286

Apps, R., and Garwicz, M. (2005). Anatomical and physiological foundations of cerebellar information processing. Nat. Rev. Neurosci. 6, 297-311. doi: 10. 1038/nrn1646

Apps, R., and Lee, S. (2002). Central regulation of cerebellar climbing fibre input during motor learning. J. Physiol. 541, 301-317. doi: 10.1113/jphysiol.2002. 016717

Armstrong, D. M., and Rawson, J. A. (1979). Activity patterns of cerebellar cortical neurones and climbing fibre afferents in the awake cat. J. Physiol. 289, 425-448.

Barmack, N. H. (1996). GABAergic pathways convey vestibular information to the beta nucleus and dorsomedial cell column of the inferior olive. Ann. N Y Acad. Sci. 781, 541-552. doi: 10.1111/j.1749-6632.1996.tb15727.x

Bazzigaluppi, P., Ruigrok, T., Saisan, P., De Zeeuw, C. I., and de Jeu, M. (2012). Properties of the nucleo-olivary pathway: an in vivo whole-cell patch clamp study. PLoS One 7:e46360. doi: 10.1371/journal.pone.0046360

Bengtsson, F., and Hesslow, G. (2006). Cerebellar control of the inferior olive. Cerebellum 5, 7-14. doi: 10.1080/14734220500462757

Bengtsson, F., and Hesslow, G. (2013). "Feedback control in the olivo-cerebellar loop," in The Handbook of the Cerebellum and Cerebellar Disorders, eds M. U. Manto, D. Gruol, J. D. Schmahmann, N. Koibuchi and F. Rossi (Dordrecht: Springer Netherlands), 1079-1099.

Bengtsson, F., Jirenhed, D., Svensson, P., and Hesslow, G. (2007). Extinction of conditioned blink responses by cerebello-olivary pathway stimulation. Neuroreport 18, 1479-1482. doi: 10.1097/wnr.0b013e3282e326e8

Best, A. R., and Regehr, W. G. G. (2009). Inhibitory regulation of electrically coupled neurons in the inferior olive is mediated by asynchronous release of GABA. Neuron 62, 555-565. doi: 10.1016/j.neuron.2009. 04.018

Bracha, V., Zbarska, S., Parker, K., Carrel, A., Zenitsky, G., and Bloedel, J. R. (2009). The cerebellum and eye-blink conditioning: learning versus network performance hypotheses. Neuroscience 162, 787-796. doi: 10.1016/j.neuroscience. 2008.12.042

Cerminara, N. L., and Rawson, J. A. (2004). Evidence that climbing fibers control an intrinsic spike generator in cerebellar Purkinje cells. J. Neurosci. 24, 4510-4517. doi: 10.1523/jneurosci.4530-03.2004

Chaumont, J., Guyon, N., Valera, A. M., Dugué, G. P., Popa, D., Marcaggi, P., et al. (2013). Clusters of cerebellar Purkinje cells control their afferent climbing fiber discharge. Proc. Natl. Acad. Sci. U S A 110, 16223-16228. doi: 10.1073/pnas. 1302310110

Colin, F., Manil, J., and Desclin, J. C. (1980). The olivocerebellar system. I. Delayed and slow inhibitory effects: an overlooked salient feature of cerebellar climbing fibers. Brain Res. 187, 3-27. doi: 10.1016/0006-8993(80)90491-6

De Zeeuw, C. I., and Berrebi, A. S. (1995). Postsynaptic targets of Purkinje cell terminals in the cerebellar and vestibular nuclei of the rat. Eur. J. Neurosci. 7, 2322-2333. doi: 10.1111/j.1460-9568.1995.tb00653.x

De Zeeuw, C. I., Hoebeek, F. E., Bosman, L. W. J., Schonewille, M., Witter, L., and Koekkoek, S. K. (2011). Spatiotemporal firing patterns in the cerebellum. Nat. Rev. Neurosci. 12, 327-344. doi: 10.1038/nrn3011

de Zeeuw, C. I., Holstege, J. C., Calkoen, F., Ruigrok, T. J., and Voogd, J. (1988). A new combination of WGA-HRP anterograde tracing and GABA 
immunocytochemistry applied to afferents of the cat inferior olive at the ultrastructural level. Brain Res. 447, 369-375. doi: 10.1016/0006-8993(88) 91142-0

De Zeeuw, C. I., and Ruigrok, T. J. (1994). Olivary projecting neurons in the nucleus of Darkschewitsch in the cat receive excitatory monosynaptic input from the cerebellar nuclei. Brain Res. 653, 345-350. doi: 10.1016/0006-8993(94)90411-1

Ekerot, C. F., Gustavsson, P., Oscarsson, O., and Schouenborg, J. (1987). Climbing fibres projecting to cat cerebellar anterior lobe activated by cutaneous A and C fibres. J. Physiol. 386, 529-538.

Garwicz, M. (1997). Sagittal zonal organization of climbing fibre input to the cerebellar anterior lobe of the ferret. Exp. Brain Res. 117, 389-398. doi: 10 1007/s002210050233

Graybiel, A. M., Nauta, H., Lasek, R. J., and Nauta, W. (1973). A cerebelloolivary pathway in the cat: an experimental study using autoradiographic tracing technics. Brain Res. 58, 205-211. doi: 10.1016/0006-8993(73) 90833-0

Gruart, A., Schreurs, B. G., del Toro, E. D., and Delgado-Garcia, J. M. (2000). Kinetic and frequency-domain properties of reflex and conditioned eyelid responses in the rabbit. J. Neurophysiol. 83, 836-852.

Heiney, S. A., Kim, J., Augustine, G. J., and Medina, J. F. (2014). Precise control of movement kinematics by optogenetic inhibition of purkinje cell activity. J. Neurosci. 34, 2321-2330. doi: 10.1523/JNEUROSCI.4547-13.2014

Hesslow, G. (1986). Inhibition of inferior olivary transmission by mesencephalic stimulation in the cat. Neurosci. Lett. 63, 76-80. doi: 10.1016/03043940(86)90016-9

Hesslow, G. (1994a). Correspondence between climbing fibre input and motor output in eyeblink-related areas in cat cerebellar cortex. J. Physiol. 476, 229-244.

Hesslow, G. (1994b). Inhibition of classically conditioned eyeblink responses by stimulation of the cerebellar cortex in the decerebrate cat. J. Physiol. 476, 245-256.

Hesslow, G., and Ivarsson, M. (1994). Suppression of cerebellar Purkinje cells during conditioned responses in ferrets. Neuroreport 5, 649-652. doi: 10 1097/00001756-199401000-00030

Hesslow, G., and Ivarsson, M. (1996). Inhibition of the inferior olive during conditioned responses in the decerebrate ferret. Exp. Brain Res. 110, 36-46. doi: $10.1007 /$ bf00241372

Hesslow, G., Svensson, P., and Ivarsson, M. (1999). Learned movements elicited by direct stimulation of cerebellar mossy fiber afferents. Neuron 24, 179-185. doi: 10.1016/s0896-6273(00)80831-4

Hesslow, G., and Yeo, C. H. (2002). "The functional anatomy of skeletal conditioning," in A Neuroscientistís Guide to Classical Conditioning, ed J. W. Moore (New York: Springer), 86-146.

Hogri, R., Segalis, E., and Mintz, M. (2014). Cerebellar inhibitory output shapes the temporal dynamics of its somatosensory inferior olivary input. Cerebellum 13, 452-461. doi: 10.1007/s12311-014-0558-3

Jacobson, G. A., Rokni, D., and Yarom, Y. (2008). A model of the olivo-cerebellar system as a temporal pattern generator. Trends Neurosci. 31, 617-625. doi: 10 . 1016/j.tins.2008.09.005

Jirenhed, D., Bengtsson, F., and Hesslow, G. (2007). Acquisition, extinction and reacquisition of a cerebellar cortical memory trace. J. Neurosci. 27, 2493-2502. doi: 10.1523/jneurosci.4202-06.2007

Jirenhed, D., and Hesslow, G. (2011a). Learning stimulus intervals-adaptive timing of conditioned purkinje cell responses. Cerebellum 10, 523-535. doi: 10 . 1007/s12311-011-0264-3

Jirenhed, D., and Hesslow, G. (2011b). Time course of classically conditioned Purkinje cell response is determined by initial part of conditioned stimulus. J. Neurosci. 31, 9070-9074. doi: 10.1523/JNEUROSCI.165311.2011

Keating, J. G., and Thach, W. T. (1995). Nonclock behavior of inferior olive neurons: interspike interval of Purkinje cell complex spike discharge in the awake behaving monkey is random. J. Neurophysiol. 73, 1329-1340.

Keating, J. G., and Thach, W. T. (1997). No clock signal in the discharge of neurons in the deep cerebellar nuclei. J. Neurophysiol. 77, 2232-2234.

Kehoe, E. J., and Macrae, M. (2002). "Fundamental behavioral methods and findings in classical conditioning," in A Neuroscientist's Guide to Classical Conditioning, ed J. W. Moore (London: Springer), 171-231.

Kellett, D. O., Fukunaga, I., Chen-Kubota, E., Dean, P., and Yeo, C. H. (2010). Memory consolidation in the cerebellar cortex. PLoS One 5:e11737. doi: 10 1371/journal.pone.0011737
Kim, J. J., Krupa, D. J., and Thompson, R. F. (1998). Inhibitory cerebello-olivary projections and blocking effect in classical conditioning. Science 279, 570-573. doi: $10.1126 /$ science. 279.5350 .570

Kimpo, R. R., Rinaldi, J. M., Kim, C. K., Payne, H. L., and Raymond, J. L. (2014). Gating of neural error signals during motor learning. Elife 3:e02076. doi: 10. 7554/eLife.02076

Lampl, I., and Yarom, Y. (1993). Subthreshold oscillations of the membrane potential: a functional synchronizing and timing device. J. Neurophysiol. 70, 2181-2186.

Lefler, Y., Yarom, Y., and Uusisaari, M. Y. (2014). Cerebellar inhibitory input to the inferior olive decreases electrical coupling and blocks subthreshold oscillations. Neuron 81, 1389-1400. doi: 10.1016/j.neuron.2014.02.032

Lepora, N. F., Porrill, J., Yeo, C. H., and Dean, P. (2010). Sensory prediction or motor control? Application of marr-albus type models of cerebellar function to classical conditioning. Front. Comput. Neurosci. 4:140. doi: 10.3389/fncom.2010. 00140

Llinás, R. (1988). The intrinsic electrophysiological properties of mammalian neurons: insights into central nervous system function. Science 242, 1654-1664. doi: 10.1126/science.3059497

Llinás, R., Leznik, E., and Makarenko, V. I. (2002). On the amazing olivocerebellar system. Ann. N Y Acad. Sci. 978, 258-272. doi: 10.1111/j.17496632.2002.tb07573.x

Llinás, R., and Yarom, Y. (1986). Oscillatory properties of guinea-pig inferior olivary neurones and their pharmacological modulation: an in vitro study. $J$. Physiol. 376, 163-182.

Maruta, J., Hensbroek, R. A., and Simpson, J. I. I. (2007). Intraburst and interburst signaling by climbing fibers. J. Neurosci. 27, 11263-11270. doi: 10 . 1523/jneurosci.2559-07.2007

Mathy, A., Clark, B. A., and Häusser, M. (2014). Synaptically induced long-term modulation of electrical coupling in the inferior olive. Neuron 81, 1290-1296. doi: 10.1016/j.neuron.2014.01.005

Mathy, A., Ho, S. S. N., Davie, J. T., Duguid, I. C., Clark, B. A., and Häusser, M. (2009). Encoding of oscillations by axonal bursts in inferior olive neurons. Neuron 62, 388-399. doi: 10.1016/j.neuron.2009.03.023

Mauk, M. D., and Ohyama, T. (2004). Extinction as new learning versus unlearning: considerations from a computer simulation of the cerebellum. Learn. Mem. 11, 566-571. doi: 10.1101/lm.83504

Mauk, M. D., Steinmetz, J. E., and Thompson, R. (1986). Classical conditioning using stimulation of the inferior olive as the unconditioned stimulus. Proc. Natl. Acad. Sci. U S A 83, 5349-5353. doi: 10.1073/pnas.83. 14.5349

McCormick, D. A., and Thompson, R. F. (1984). Cerebellum: essential involvement in the classically conditioned eyelid response. Science 223, 296-299. doi: 10. $1126 /$ science.6701513

Medina, J. F., Garcia, K. S., and Mauk, M. D. (2001). A mechanism for savings in the cerebellum. J. Neurosci. 21, 4081-4089.

Medina, J. F., Nores, W. L., and Mauk, M. D. (2002). Inhibition of climbing fibres is a signal for the extinction of conditioned eyelid responses. Nature 416, 330-333. doi: $10.1038 / 416330$ a

Miall, R. C., Keating, J. G., Malkmus, M., and Thach, W. T. (1998). Simple spike activity predicts occurrence of complex spikes in cerebellar Purkinje cells. Nat. Neurosci. 1, 13-15. doi: 10.1038/212

Najafi, F., and Medina, J. F. (2013). Beyond “all-or-nothing” climbing fibers: graded representation of teaching signals in Purkinje cells. Front. Neural Circuits 7:115. doi: 10.3389 /fncir.2013.00115

Napier, R. M., Macrae, M., and Kehoe, E. J. (1992). Rapid reaquisition in conditioning of the rabbit's nictitating membrane response. J. Exp. Psychol. Anim. Behav. Process. 18, 182-192. doi: 10.1037//0097-7403.18.2.182

Nelson, B., and Mugnaini, E. (1989). "Origins of GABA-ergic inputs to the inferior olive," in The Olivocerebellar System in Motor Control, ed P. Strata (Berlin: Springer Verlag), 90-102.

Rasmussen, A., and Hesslow, G. (2014). Feedback control of learning by the cerebello-olivary pathway. Prog. Brain Res. 210, 103-119. doi: 10.1016/b978-0444-63356-9.00005-4

Rasmussen, A., Jirenhed, D., and Hesslow, G. (2008). Simple and complex spike firing patterns in Purkinje cells during classical conditioning. Cerebellum 7, 563 566. doi: 10.1007/s12311-008-0068-2

Rasmussen, A., Jirenhed, D., Zucca, R., Johansson, F., Svensson, P., and Hesslow, G. (2013). Number of spikes in climbing fibers determines the direction of 
cerebellar learning. J. Neurosci. 33, 13436-13440. doi: 10.1523/ineurosci.152713.2013

Salafia, W., Lambert, R., Host, K., Chiala, N., and Ramirez, J. (1980). Rabbit nictitating membrane conditioning: lower limit of the effective interstimulus interval. Anim. Learn. Behav. 8, 85-91. doi: 10.3758/bf03209734

Sears, L. L., and Steinmetz, J. E. (1991). Dorsal accessory inferior olive activity diminishes during acquisition of the rabbit classically conditioned eyelid response. Brain Res. 545, 114-122. doi: 10.1016/0006-8993(91) 91276-7

Steinmetz, J. E., Rosen, D. J., Chapman, P. F., Lavond, D. G., and Thompson, R. F. (1986). Classical conditioning of the rabbit eyelid response with a mossy-fiber stimulation CS: I. Pontine nuclei and middle cerebellar peduncle stimulation. Behav. Neurosci. 100, 878-887. doi: 10.1037//0735-7044.100.6.878

Svensson, P., Bengtsson, F., and Hesslow, G. (2006). Cerebellar inhibition of inferior olivary transmission in the decerebrate ferret. Exp. Brain Res. 168, 241-253. doi: 10.1007/s00221-005-0086-y

Vallbo, A. B., and Wessberg, J. (1993). Organization of motor output in slow finger movements in man. J. Physiol. 469, 673-691.

Wetmore, D. Z., Jirenhed, D., Rasmussen, A., Johansson, F., Schnitzer, M. J., and Hesslow, G. (2014). Bidirectional plasticity of Purkinje cells matches temporal features of learning. J. Neurosci. 34, 1731-1737. doi: 10.1523/jneurosci.2883-13. 2014
Yang, Y., and Lisberger, S. G. (2014). Purkinje-cell plasticity and cerebellar motor learning are graded by complex-spike duration. Nature 510, 529-532. doi: 10. 1038/nature13282

Yeo, C. H., Hardiman, M. J., and Glickstein, M. (1984). Discrete lesions of the cerebellar cortex abolish the classically conditioned nictitating membrane response of the rabbit. Behav. Brain Res. 13, 261-266. doi: 10.1016/0166-4328(84)90168-2

Conflict of Interest Statement: The authors declare that the research was conducted in the absence of any commercial or financial relationships that could be construed as a potential conflict of interest.

Received: 20 December 2013; accepted: 09 July 2014; published online: 05 August 2014. Citation: Rasmussen A, Jirenhed D-A, Wetmore DZ and Hesslow G (2014) Changes in complex spike activity during classical conditioning. Front. Neural Circuits 8:90. doi: $10.3389 /$ fncir.2014.00090

This article was submitted to the journal Frontiers in Neural Circuits.

Copyright $\odot 2014$ Rasmussen, Jirenhed, Wetmore and Hesslow. This is an open-access article distributed under the terms of the Creative Commons Attribution License (CC $B Y)$. The use, distribution or reproduction in other forums is permitted, provided the original author(s) or licensor are credited and that the original publication in this journal is cited, in accordance with accepted academic practice. No use, distribution or reproduction is permitted which does not comply with these terms. 